This item was submitted to Loughborough's Research Repository by the author.

Items in Figshare are protected by copyright, with all rights reserved, unless otherwise indicated.

\title{
UK adults exhibit higher step counts in summer compared to winter months
}

PLEASE CITE THE PUBLISHED VERSION

http://dx.doi.org/10.1080/03014460801908058

\section{PUBLISHER}

(c) Informa UK Ltd.

\section{VERSION}

AM (Accepted Manuscript)

\section{LICENCE}

CC BY-NC-ND 4.0

\section{REPOSITORY RECORD}

Hamilton, Sarah L., Stacy A. Clemes, and Paula L. Griffiths. 2019. "UK Adults Exhibit Higher Step Counts in Summer Compared to Winter Months". figshare. https://hdl.handle.net/2134/15272. 
This item was submitted to Loughborough's Institutional Repository (https://dspace.lboro.ac.uk/) by the author and is made available under the following Creative Commons Licence conditions.

\section{creative
commons}

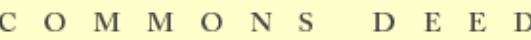

Attribution-NonCommercial-NoDerivs 2.5

You are free:

- to copy, distribute, display, and perform the work

Under the following conditions:

Attribution. You must attribute the work in the manner specified b the author or licensor.

Noncommercial. You may not use this work for commercial purposes.

No Derivative Works. You may not alter, transform, or build upon this work.

- For any reuse or distribution, you must make clear to others the license terms of this work.

- Any of these conditions can be waived if you get permission from the copyright holder.

Your fair use and other rights are in no way affected by the above.

This is a human-readable summary of the Leqal Code (the full license).

\section{Disclaimer 만}

For the full text of this licence, please go to: http://creativecommons.org/licenses/by-nc-nd/2.5/ 
UK adults exhibit higher step counts in summer compared to winter months

Running Head: Seasonal variation in adult step counts

Keywords: Ambulatory activity, pedometer, seasonal, adults

Authors: Sarah L Hamilton, Stacy A Clemes and Paula L Griffiths

Address of all authors:

Department of Human Sciences

Loughborough University

Leicestershire

UK

LE11 3TU

\section{Corresponding author:}

Stacy A Clemes, address as above.

Email: S.A.Clemes@lboro.ac.uk

Telephone: 01509228170

Fax: $\quad 01509223940$ 


\section{Abstract}

Background: Seasonal differences in step counts have been observed in a limited number of studies conducted on US adults. Due to the diverse global climate, assessment and interpretation of seasonal patterns in ambulatory activity may vary between countries, and regionally specific studies are necessary to understand global patterns. Currently, no studies have assessed whether a seasonal trend is present when ambulatory activity is measured objectively in adults living in the UK.

Aim: To investigate whether pedometer-determined step counts of adults living in the UK vary between summer and winter.

Subjects and methods: Ninety-six adults (52\% male, age $=41.0 \pm 12.3$ years, $\mathrm{BMI}=26.1 \pm$ $5.1 \mathrm{~kg} / \mathrm{m}^{2}$ ) completed a within-subject bi-seasonal pedometer study. All participants completed two four-week monitoring periods; one during the summer and one the following winter. The same Yamax SW-200 pedometer was worn throughout waking hours during both seasons, and daily step counts were recorded in an activity log. Intra-individual seasonal changes in mean daily steps were analysed using a paired samples $t$-test.

Results: Summer mean daily step counts (10417 \pm 3055 steps/day) were significantly higher than those reported during the winter $(9132 \pm 2841$ steps/day) $(p<0.001)$. A follow-up study conducted the subsequent summer in a sub-sample $(n=28)$ reinforced this trend. Summer step counts were significantly higher than winter step counts on all days of the week $(p \leq$ 0.001). A significant day of the week effect was present in both seasons, with step counts reported on a Sunday being on average 1,500 steps/day lower than those reported Monday through to Saturday.

Conclusion: Step counts in the sample of UK adults surveyed decreased significantly in the winter compared to the summer, suggesting future pedometer surveillance studies should capture step counts throughout the year for a non-biased reflection of habitual ambulatory 
activity. Public health initiatives should target these seasonal differences and opportunities should be provided which encourage individuals to increase their activity levels during the colder, darker months of the year. 


\section{Introduction}

Obesity levels in the UK are rising, approximately $24 \%$ of male and female adults living in the UK were classified as obese in 2004 (characterised by a body mass index [BMI] $\geq 30$ $\mathrm{kg} / \mathrm{m}^{2}$ (WHO 2000)), compared with $14 \%$ of males and $17 \%$ of females classified as obese in 1994 (Department of Health 2005). This increasing trend is allied with a heavy financial burden on the health service, which is estimated to cost approximately $£ 7$ billion per annum (House of Commons Health Committee 2004), due to the augmented disease risk associated with excess body fat. Numerous chronic diseases including coronary heart disease, type 2 diabetes, hypertension and certain cancers can be influenced by an obese state (Haslam and James 2005). Physical inactivity is widely documented as a major risk factor for obesity (Hill and Melanson 1999), and despite attempts to disseminate this knowledge to the general population, it is predicted that about two-thirds of UK males and three-quarters of UK females do not attain physical activity levels required for health benefits (undertaking a minimum of 30 minutes of at least moderate intensity activity, at least five times per week) (Department of Health 2005). It is therefore essential to understand the activity patterns of these at risk individuals, in order to appropriately target public health initiatives.

Physical activity levels tend to fluctuate according to season, being characteristically highest during the summer and lowest during the winter. This seasonal pattern has been well defined in large scale self-report studies, which have examined changes in leisure-time, occupational and household activity, in the USA (Dannenberg et al. 1989; CDC 1997; Matthews et al. 2001; Pivarnik et al. 2003) and UK (Uitenbroek 1993). Self-report measures of physical activity can however lack validity in that individuals often exhibit an inability to accurately self-assess low intensity activities, such as walking behaviour (Sallis and Saelens 2000). This may have implications for the use of self-report measures in sedentary societies. Walking is 
reportedly the most prevalent form of physical activity in both US (Simpson et al. 2003) and UK adults (Chief Medical Officer 2004). However, walking is commonly underestimated through questionnaires (Ainsworth et al. 1993; Richardson et al. 1994; Bassett et al. 2000). By not capturing walking, or ambulatory, behaviour adequately, self-report studies may lack the sensitivity needed to detect the actual seasonal physical activity experience of many individuals.

Pedometers are rapidly gaining popularity in the research domain. The combination of their low cost, small size, simplicity and unobtrusive nature make them practical tools for objectively monitoring ambulatory activity in the free-living environment. Although accurate in measuring steps (Bassett et al. 1996), pedometers are not designed to capture short-term patterns in activity (<24 hours), intensity, or type of exercise (Tudor-Locke et al. 2002). The standardised steps per day unit of measurement enjoys universal interpretation, facilitating reliable cross-population comparisons. This type of comparison is often limited when using subjective measures (Lamb and Brodie 1990). However, despite the potential for pedometers to measure activity, to date there is limited data available describing the seasonal patterns in ambulatory activity of healthy free-living adults.

Previous studies that have objectively assessed seasonal variability in ambulatory activity have been limited by either gender and duration (Lee et al. 1987), study aim (Chan et al. 2006) or sample size (Tudor-Locke et al. 2004a). Lee et al. (1987) compared summer and winter pedometer data collected in Kentucky, from 130 females aged 51 to 86 years, over two seasonally separate seven day monitoring frames. A significant summer to winter reduction in steps was reported in the form of distance walked. Chan et al. (2006) conducted a pedometer-based intervention with the aim to raise activity levels in Canadian adults $(n=$ 
203). Step count data were collected from two groups of participants, data from one group were collected between the months of March and July, and data from the second group were collected between December and April. Although a seasonal change in step counts was observed, the study aim was to increase walking activity and therefore it is unlikely that habitual levels were captured. Tudor-Locke et al. (2004a) assessed daily step counts reported over a continuous 365 day period in 23 US male and female adults. Although this preliminary study indicated a winter reduction in steps, the authors acknowledge the need for research to be conducted in a larger sample to confirm their findings.

All research to date investigating seasonal changes in ambulatory activity (outlined above) has focused exclusively on North American populations, and very little research has been published investigating pedometer-determined activity in healthy, free-living UK adults. From the research available, using pedometers in UK adults, Clemes et al. (2007; 2008a) reported that mean daily step counts, measured in normal-weight, overweight and obese UK adults were higher, by approximately 3000 steps/day, than those observed in US adults. This suggests that there are potentially differences in activity levels between UK and US adults. No research has yet investigated seasonal changes in ambulatory activity of UK adults.

Seasonal changes in physical activity are thought to be mediated through changes in the environment, with ambient temperature, daylight hours and precipitation considered most influential (CDC 1997; Merrill et al. 2005). Due to the diverse global climate, assessment and interpretation of seasonal patterns in ambulatory activity may vary between countries, and regionally specific studies are necessary to understand global patterns. For example, the climate in the UK is very different to the climate in the US. Climate data collected over a 30 year period in the UK show that minimum and maximum temperatures during summer and 
winter range between $10.3^{\circ} \mathrm{C}$ to $19.9^{\circ} \mathrm{C}$ (summer) and $1.0^{\circ} \mathrm{C}$ to $6.7^{\circ} \mathrm{C}$ (winter), respectively (Met Office, 2006). In contrast, climate data collected over the same time period from the state of South Carolina (one of the two locations used in the study by Tudor-Locke et al. (2004a)) show minimum and maximum temperatures between $21.8^{\circ} \mathrm{C}$ to $31.6^{\circ} \mathrm{C}$ and $4.1^{\circ} \mathrm{C}$ to $15.6^{\circ} \mathrm{C}$ in summer and winter respectively (Met Office, 2006).

Given the number of sedentary adults and the rising problem of obesity in the UK, it is important to understand seasonal physical activity patterns of UK adults in order to develop appropriate public health initiatives. The aim of the current study therefore was to measure the seasonal variation in ambulatory activity of free-living UK adults, by comparing pedometer determined activity levels, collected over the summer and winter months.

\section{Methods}

\section{Experimental design}

A within-subjects repeated measures design was employed, which consisted of two methodologically identical data collection periods. The first period of data collection took place during the summer of 2005 , between the $21^{\text {st }}$ June and the $22^{\text {nd }}$ September. The data collected during this time period has been reported elsewhere (Clemes et al. 2007). Participants were recalled and requested to repeat the 'summer' study during the following winter. The winter data collection period took place between the $20^{\text {th }}$ January 2006 and $21^{\text {st }}$ March 2006. This paper details exclusively those participants who completed both the summer and winter monitoring periods $(n=96)$. 


\section{Participants}

Participants were recruited during the summer of 2005 from two different counties in the United Kingdom - Leicestershire $(n=70)$ and Cornwall $(n=52)$ - through advertisements placed in local media. An equal number of male and female adult participants were recruited using a quota-based sampling frame that was developed to achieve an even spread of individuals across the age range of 18 to 65 years. The sampling frame also ensured that, at the study outset, an equal number of participants were classified as either normal weight (BMI < 25) or overweight (BMI $\geq 25$ ), to reflect the 2004 prevalence of overweight in UK adults (Department of Health 2005).

Upon completion of the summer monitoring frame participants were asked if they would be willing to repeat the procedure the following winter. Eight participants indicated that they would not be available during the designated winter testing period, the remaining 114 participants consented and were re-approached the following autumn via email or telephone. Winter study exclusion criteria encompassed any non-seasonal lifestyle change made since completion of the summer study which may affect physical activity levels. Participants were screened for Seasonal Affective Disorder (Partonen and Lonnqvist 1998). Ninety-nine participants started the winter monitoring period, 6 participants did not respond to the followup invitation made in the autumn and a further 9 participants met winter exclusion criteria. Reasons for exclusion were; moved away from the monitoring area $(n=6)$, divorced since the summer monitoring frame resulting in changes to daily routine, not associated with the season ( $n=1)$, had a demobilising injury $(n=1)$, changed occupation $(n=1)$.

Responses on a health screen questionnaire completed prior to each monitoring period confirmed that participants were all in good general health and none had any physical illness 
or disability that might affect their normal daily routine. The study received ethical approval from the Loughborough University Ethical Advisory Committee. Participants received written and oral details outlining the study protocol and provided written informed consent.

\section{Anthropometric and body composition measurements}

Prior to, and following the summer and winter monitoring periods, body weight and percentage body fat were measured in the laboratory using a Tanita Segmental Body Composition Analyser BC-418MA (Tanita UK Ltd, Middlesex), that measures body composition using 8-point bio-impedance analysis. This system correlates highly with the reference measure of dual-energy x-ray absorptiometry (Pietrobelli et al. 2004). Height, without shoes, was measured during the initial summer study only due to the low rate of adult height change (Sorkin et al. 1999), using a wall mounted stadiometer (Seca UK, Model: 206, Birmingham, Warwickshire, UK). BMI was calculated as weight (kg) divided by height (m) squared $\left(\mathrm{kg} / \mathrm{m}^{2}\right)$.

\section{Physical activity assessment}

Participants were issued with the same New Lifestyles Digi-Walker SW-200 pedometer during both monitoring periods to avoid potential inter-pedometer error (for $4.8 \%$ of participants a single pedometer used cross-season was not possible due to the instrument becoming; lost $(n=3)$ or broken $(n=2))$. However, these pedometers were replaced with the same model of pedometer.

The SW pedometer range has been shown to accurately detect steps in controlled laboratory (Le Masurier and Tudor-Locke 2003; Swartz et al. 2003; Melanson et al. 2004) and free- 
living conditions (Le Masurier et al. 2004; Schneider et al. 2004) and has consequently been employed in numerous free-living activity studies (Chan et al. 2004; Tudor-Locke et al. 2004b; Hornbuckle et al. 2005). The pedometer accurately assesses walking activity of all BMI classifications (Swartz et al. 2003).

The same protocol was employed during both seasons. Participants were instructed to wear the pedometer during waking hours over a continuous four-week period, removing only while bathing, showering or swimming. An activity log was supplied in which individuals recorded their daily step count at the end of each day, along with their responses to the following two questions; 1) 'Did you go for a walk today? If yes, for how long (mins)' and, 2) 'Did you do any other physical activity today? If yes, please provide a brief description of type and duration'. Participants were asked to complete the log in the same manner during both monitoring periods and encouraged to maintain normal daily activity levels throughout. Upon completion of each monitoring period, participants completed a brief post-study questionnaire enquiring whether they had suffered from any ill health or made changes to their normal routine, diet or general activity levels during the monitoring frame. Post questionnaire data showed all participants remained in good health during both the summer and winter monitoring periods and no changes to daily routine or lifestyle were reported.

\section{Meteorological information associated with each monitoring frame}

Meteorological information was collected retrospectively, in the form of summary data, from the Met Office following data collection. Data summarising the mean, minimum and maximum temperature $\left({ }^{\circ} \mathrm{C}\right)$ along with sunshine hours and rainfall volume $(\mathrm{mm})$ were collected that corresponded to the summer 2005 and winter 2006 monitoring periods. 


\section{Data and statistical methods}

Of the 122 participants who completed the summer monitoring frame, $79 \%$ also completed the winter monitoring frame. To ensure the participants completing both monitoring frames did not differ to those completing the summer only, the two groups were compared in terms of mean summer step counts and pre-summer study BMI using independent samples $t$-tests. The gender splits of the two groups were compared using multi-dimensional Chi-squared statistics with cross-tabulations.

The remainder of this section describes the statistical procedures employed for those participants completing both the summer and winter monitoring periods. Baseline measures of BMI and percentage body fat collected prior to the summer and winter monitoring periods, and changes in BMI and percentage body fat over the two independent four-week monitoring periods were compared using paired samples $t$-tests.

In the event that a participant forgot to record their step count value in the activity log, missing values (1\%) were input using season-specific and participant-specific day of the week averages (all missing values were calculated using 3 values). This procedure to deal with missing values has been adopted elsewhere and enables more powerful statistical analyses (Rowe et al. 2004; Tudor-Locke et al. 2004a).

Season-specific mean daily step counts were calculated for each participant by averaging the complete set of 28 step count values, and summer to winter differences in mean daily step counts were analysed using a paired samples $t$-test. Effect size of steps per day was cal culated to ascertain the size of the difference in step counts between seasons (Field 2005). 
Mean daily step counts reported on each day of the week (Monday to Sunday) were calculated for each season by averaging the 4 step count values available for each day. A repeated measures ANOVA (with Greenhouse-Geisser correction applied) was employed to assess whether step counts varied according to the day of the week within each season. Bonferroni adjusted pairwise comparisons were performed in the event of a significant day of the week effect. Mean step counts reported on each day of the week were compared between seasons (e.g. summer mean Monday steps versus winter mean Monday steps etc.) using multiple paired samples $t$-tests, with a Bonferroni correction applied. Day-specific seasonal changes in steps were also calculated (e.g. winter mean Monday steps minus summer mean Monday steps). A repeated measures ANOVA was applied to assess whether the magnitude of seasonal change in steps varied according to the day of the week. Gender differences in overall mean daily step counts for each season were assessed using independent samples $t$ tests. The following interaction, gender-by-season-by-day of the week, was tested using a 3way ANOVA.

In the event a participant forgot to record their activity log data (self-reported walking and other exercise), missing values (walking 1\%, other data $2 \%$ ) were input using season-specific and participant-specific day of the week averages (all missing values were computed from $\geq 3$ values). Due to the high level of positive skew observed, time spent walking and minutes engaged in other activity, reported in the activity log, are described by the median and interquartile range for each season. Wilcoxon Signed Ranked Tests were used to statistically assess summer to winter differences in self-reported activity levels.

Statistical analyses were conducted using SPSS for Windows version 13.0 (SPSS Inc., Chicago, Il). Differences were considered to be statistically significant at $p \leq 0.05$ level (twotailed). 


\section{Follow-up-study}

A sub-sample of participants from the main study (28 out of 96) agreed to participate in a follow-up study conducted during the summer of 2006. The aim of this follow-up study was to confirm any seasonal changes observed during the main study and to establish any possible ordering effects that might have been influenced by pedometer reactivity. The protocol followed was exactly the same as that outlined for the previous two monitoring frames, and the same exclusion criteria applied to the winter study were also applied to this follow-up. All participants included in this sub-study remained healthy throughout according to poststudy questionnaire results. Participants who completed the follow-up were compared to those who did not take part in this additional study using independent samples $t$-tests. Mean daily step counts taken by this sub-sample only, during each of the three monitoring frames, were compared using a repeated measures ANOVA and Bonferroni adjusted pairwise comparisons were performed in the event of a significant seasonal effect.

\section{Results}

\section{Meteorological information}

Meteorological data summarising the mean, minimum and maximum temperature $\left({ }^{\circ} \mathrm{C}\right)$ along with sunshine hours and rainfall volume $(\mathrm{mm})$ recorded by the Met Office during the two monitoring periods (Summer 2005 and Winter 2006) are shown in Table I. As anticipated, there was a marked decrease in both temperature and sunshine hours from summer to winter, whilst rainfall volume remained relatively constant between seasons. 


\section{Participants}

Of the 99 participants who started the winter monitoring period, 3 were lost to follow-up. Ninety-six participants $(78.6 \%$ of those used in the analysis of the summer monitoring period), completed both the summer and winter monitoring frames. Participants who completed only the summer section of the study did not differ significantly to those who completed both the winter and summer sections with respect to; summer mean daily step count, pre-summer study BMI or gender proportion $(p>0.05)$.

Participants who completed both summer and winter monitoring frames had a mean age of $41.0 \pm 12.3$ years and consisted of 46 males and 50 females. Season specific anthropometric and step count data are presented in Table II. A significant summer to winter increase in BMI and percentage body fat was observed. No significant changes in BMI and percentage body fat were observed over either of the two four-week monitoring periods (results not shown).

\section{INSERT TABLE II ABOUT HERE}

Change in mean daily steps- summer versus winter

Participants recorded 5,323 person-days of step count data out of a possible 5,376 persondays (99\% compliance), meaning $1 \%$ of values had to be input based upon season-specific and participant-specific day of the week averages. Corrected (missing values replaced) mean steps/day and raw steps/day data were very similar (summer corrected $=10417 \pm 3055$ vs. summer raw $=10419 \pm 3054$, winter corrected $=9132 \pm 2840 v s$. winter raw $=9132 \pm 2833$ ).

Mean winter daily steps counts were markedly lower than mean summer daily step counts $(t=$ -6.627, $p<0.001$ ), this significant cross-seasonal difference is evident throughout the two 28 
day monitoring periods (Figure 1), with an average winter reduction in ambulatory activity of 1,286 steps per day. This resulted in an effect size of 0.56 . During the summer monitoring period $50 \%$ of the sample reported a mean daily step count above the recommended 10,000 steps/day (Tudor-Locke and Bassett 2004), whilst this proportion fell to $34 \%$ during the winter monitoring period.

\section{INSERT FIGURE 1 ABOUT HERE}

\section{Day-of-the-week variation}

Table III. presents the mean daily step counts reported on each day of the week during both the summer and winter monitoring periods, along with the seasonal change in step counts occurring on each day of the week. Participants showed a consistent summer to winter reduction in mean step counts on every day of the week $(p \leq 0.001)$, and the magnitude of seasonal change did not vary significantly between days of the week. Step counts reported on a Sunday were significantly lower than those reported on all other days during both seasons ( $p$ $<0.05$, see Table. III)

INSERT TABLE III ABOUT HERE

\section{Gender differences}

There was a tendency for males to report higher mean daily step counts than their female counterparts during both seasons, (summer mean daily step counts: males $=11061 \pm 3507$ steps/day vs. females $=9867 \pm 2479$ steps/day, $t=1.839, p=0.07$, and, winter mean daily step counts: males $=9764 \pm 3198$ steps/day vs. females $=8550 \pm 2352$ steps/day, $t=2.104, p$ $=0.038$ ). The magnitude of step count change between seasons was similar for both genders 
and there was no statistically significant gender effect $(p=0.868)$. In addition, there was no significant gender-by-season-by-day of the week interaction (data not shown).

\section{Seasonal variability in self-reported walking and other physical activity}

One participant was excluded from this part of the analysis $(n=95)$ as activity logs were not completed in a comparative manner between both seasons; occupational walking was reported during one season only. The median (inter-quartile range) time spent engaged in self-reported walking behaviour during the summer was $13.8(5.9,27.3)$ minutes/day compared to $7.9(0.7$, 17.1) minutes/day during the winter. This resulted in a significant summer to winter reduction in self-reported walking behaviour in the range of $43 \%(z=-4.377, p<0.001)$. Levels of self-reported 'other' physical activity were $6.4(0,18.8)$ minutes/ day during the summer, reducing to $4.3(0,19.1)$ minutes/day during the winter, this reduction was not statistically significant $(z=-1.418, p>0.05)$.

\section{Follow-up study}

Participants who completed the follow-up study $(n=28)$ did not differ significantly from the remainder of the sample with regards to summer 2005 mean daily step counts (follow-up participants $=10466 \pm 2533$ steps $/$ day vs. remaining participants $=10397 \pm 3262$ steps $/$ day, $p$ $=0.920$ ) or winter mean daily step counts (follow-up participants $=9051 \pm 2743$ steps/ day vs . remaining participants $=9165 \pm 2900$ steps/day, $p=0.859$ ). The step count data collected in this follow-up study, conducted during the summer of 2006, confirmed the seasonal variation in step counts observed in the main study. Mean daily step counts reported during the two summer monitoring periods, in this sub-sample, did not differ significantly (summer $2005=$ $10466 \pm 2533$, vs. summer $2006=10149 \pm 3019, p=0.378$ ), whilst mean daily step counts 
reported in the winter $(9051 \pm 2743)$ for this sub-sample were significantly lower than those reported during both summer monitoring periods $(p \leq 0.001)$.

\section{Discussion}

The aim of this study was to determine whether step counts from a sample of adults living in the UK vary between summer and winter. There was a clear seasonal difference in ambulatory activity occurring in the sample studied, with winter levels being significantly lower than summer levels by approximately 1,300 steps/day. The seasonal change in step counts is not only statistically significant, but represents a medium to large effect size (Field 2005). The present study substantiates the preliminary work of Tudor-Locke et al (2004a) who also observed a summer to winter step count reduction in the range of 900 steps/day in a small sample of US adults $(n=23)$. The discrepancy between the two studies, in terms of the magnitude of seasonal changes in steps, is not unexpected due to the high level of interregional variability in habitual step counts (Sequeira et al. 1995; Tudor-Locke et al. 2004b; Dwyer et al. 2007) and further underlines the need for region-specific seasonality studies.

The change in ambulatory activity, between summer and winter, observed in this pedometerbased study is consistent with seasonal patterns reported in qualitative questionnaire-based studies, which measure a broader range of physical activities (Dannenberg et al. 1989; Uitenbroek 1993; CDC 1997; Matthews et al. 2001; Pivarnik et al. 2003). This paper objectively measured the seasonal variation in steps accumulated throughout the day, with all forms of steps contributing to the daily total. Due to the unstandardised nature of questionnaire-based studies however, no direct comparison can be made between the $12.3 \%$ seasonal change in step counts noted in the current study and the variation in walking behaviour reported subjectively. Uitenbroek (1993) only recorded walking activity lasting 
more than 20 minutes, and observed a 1\% seasonal change in the number of UK respondents reporting participation in walking. In contrast, when assessing seasonal changes in total minutes spent walking for pleasure, Dannenberg (1989) reported a 60\% reduction from summer to winter in US adults.

Preliminary indices have recently been constructed to classify pedometer-determined physical activity levels according to the number of steps taken per day (Tudor-Locke and Bassett 2004). With respect to the mean daily step counts reported in this study, the participants could on average, be described as ‘active’ during the summer (10417 \pm 3055 steps/day), as mean steps taken fell within the range of 10,000 and 12,500 steps/day and, 'somewhat active' during the winter (9132 \pm 2841 steps/day), as mean steps taken fell within the range of 7,500 to 9,999 steps/day. In the summer monitoring period 50\% of participants reported mean daily step counts above the recommended 10,000 steps/day, whilst in the winter only $34 \%$ of the sample achieved this goal. In addition to any health consequences of seasonally interrupting physical activity (discussed below), the findings of the current study also have methodological implications in that data collection restricted to one season may either overestimate or underestimate year round habitual ambulatory activity (as illustrated above). In order to obtain a non-biased reflection of general day-to-day step count levels, pedometer studies should be conducted throughout the year.

Due to the dose-response relationship between physical activity and health (Blair et al. 1992), any seasonal reduction in activity has the potential to impact negatively on health. It has been hypothesised that by stopping exercise behaviour for 'the winter period' a permanent reduction in activity may result (Uitenbroek 1993). Seasonal changes in physical activity may therefore have the potential to affect obesity prevalence and the health risks associated with 
this rapidly growing epidemic in the UK. Furthermore, Magnus et al. (1979) reported that by seasonally interrupting walking, cycling or gardening activities for several months of the year ( $>$ 4months) any protective benefits against acute coronary events accumulated by sustained activity throughout the rest of the year are reduced. Therefore with respect to ambulatory activity, walking should be habitually maintained (for $\geq 8$ months of the year) for protection to be conferred.

Beyond the physical health benefits of activity there may also be mental health benefits. Mental well-being exhibits seasonality, deteriorating during the winter months (Shin et al. 2005). Maintaining physical activity levels throughout the winter have been shown to somewhat attenuate this seasonal fluctuation (Suter et al. 1991; Huttunen et al. 2004). It is hypothesised therefore that by sustaining daily step counts in the winter there could be benefits for some individuals of improved mood. However, further research is required to evaluate this.

The present study employed two different measures of walking activity, objective step counts and self-reported walking duration. The clear disagreement between the two methods may reflect the inability of self-report to capture ubiquitous walking and everyday activity which has an influential role in preventing unhealthy weight gain (Tudor-Locke and Myers 2001). Time spent walking was greater than time spent in all other leisure-time activities, (which included swimming, football, exercise classes), during both seasons, enforcing the popularity of walking as a means to increase activity levels (Chief Medical Officer 2004).

The summer to winter variation in ambulatory activity reported in this paper, reflect changes in ambient temperature and sunshine hours measured in the UK at the time of each 
monitoring frame. Inter-seasonal differences in climate were observed with mean temperature and sunshine hours recorded during the two monitoring frames decreasing by at least three-fold from summer to winter. This was mirrored by a decrease in step counts occurring from summer to winter. Similar observations have been reported with respect to self reported leisure-time activity (Van Staveren et al. 1986; CDC 1997). Rainfall was relatively constant during both seasons, it is noted however that data were available for rainfall volume only, not the number of precipitation days which is in general higher during winter months in the UK (Met Office 2006). A limitation of the current study is the fact that only seasonal summaries of meteorological data were available, and thus it was not possible to statistically assess any relationships between step counts and the climate. Future studies should overcome this shortfall by recording daily weather conditions concurrently with step count data.

Significantly fewer steps were taken on Sundays compared to all other days of the week during both seasons. On average participants took 1,560 steps/day less on a Sunday than all other days of the week during the summer and 1,286 steps/day less during the winter. This finding is consistent with reports from US (Tudor-Locke et al. 2005) and Belgian (Cardon et al. 2006) adults whereby Sunday activity has been noted as significantly lower by 1,250 and 677 steps/day respectively. This simple day of the week activity pattern whereby activity reduces on a Sunday does not appear to be random but an inherent behavioural characteristic of free-living individuals year round across settings. These findings further substantiate the need for physical activity interventions that target Sundays year round (Clemes et al. 2007).

The high mean daily step count standard deviations observed in this paper are characteristic of pedometer based surveillance studies and reflect inter- and intra-individual variability in 
behaviour. Other pedometer-based surveillance studies conducted in the USA (Tudor-Locke et al. 2004b), Finland (control group from a physical activity intervention) (Aittasalo et al. 2004), Belgium (Cardon et al. 2006), Australia (Dwyer et al. 2007) and Switzerland (Sequeira et al. 1995) all reported similar levels of daily step count variability, as shown by their reported standard deviations, which were all in the region of 3,000-4,000 steps/day. Similarly, the same studies have shown that high standard deviations remain a characteristic of pedometer data when samples are stratified by gender, age, occupation, self-reported physical activity level, racial grouping, day of the week and BMI.

Due to their self-monitoring nature, long-term free-living pedometer studies are dependent upon participants' honesty and commitment to correctly reporting their daily step count. As all participants used in the current study had previously completed an identical monitoring period in the summer (Clemes et al. 2007), and willingly agreed to take part in the winter follow-up, it is anticipated that this will have minimised any concerns regarding participant commitment and honesty, in terms of step count recording, in these data. In consideration of this point, a limitation of the current study is the fact that participants were all volunteers who were aware at the study outset that they were going to be requested to wear a pedometer and record their daily step counts throughout the monitoring period. It is likely therefore that, due to this self-selection, our participants may have been more motivated than the general population to wear a pedometer over an extended period of time, and to monitor their physical activity. It must be considered therefore that the habitual activity levels of those engaged in this study may have been biased, and the actual step count values reported in this paper may overestimate the general UK population's activity level. Despite this, it is extremely likely that the seasonal trend observed is a true reflection of the general population's experience. 
Volunteer based studies often recruit people of a higher socio-economic status (SES). In this sample the SES was relatively diverse. Using participants' postcode to characterise the SES of the area in which they reside, it was observed that our sample came from neighbourhoods where unemployment ranged from $0.8 \%$ to $7 \%$, relative to the national average of $3.4 \%$, and the percentage of people in good health, in these neighbourhoods, ranged from $50 \%$ to $83 \%$, relative to the national average of $68.8 \%$ (Neighbourhood Statistics, 2007). Based upon participants' occupation, $40.6 \%$ and $38.5 \%$ of our sample can be categorised as white and blue collar workers respectively, while $20.9 \%$ of the sample were categorised as non-working (including students, housewives/househusbands, and retired individuals).

The term 'pedometer reactivity' is used to describe any change in walking behaviour that occurs in response to wearing a pedometer, in surveillance studies this issue may be a potential compromise to validity (Clemes et al. 2008b). Currently however there are conflicting findings on the presence/absence of pedometer reactivity in adults (Matevey et al. 2006; Behrens and Dinger 2007; Clemes et al. 2008b). Eastep et al. (2004) have suggested that if pedometer reactivity exists, it will dissipate within approximately two weeks of monitoring. By employing an extensive four-week monitoring frame, habitual activity levels are more likely to be captured. No changes in percent body fat and BMI were seen over either monitoring frames suggesting habitual lifestyle patterns were maintained throughout the two surveillance periods. The sub-study reinforced the seasonal trend (summer steps $>$ winter steps) displayed in the main study, confirming the difference seen between the two seasons was attributable to the season and not a function of reactivity due to participants initial interaction with the pedometer, and step count recording, in the summer of 2005. 
Limitations of the current study include the fact that data were collected from only two regions in the UK, from a relatively limited sample size. It would be useful to repeat the study with a larger sample and with a greater number of UK areas represented. Participation was voluntary, therefore at the initial recruitment stage self-selection may have occurred, as discussed above. A further limitation, common to pedometers, is the fact that they do not measure physical activity using only upper body movements, neither do they measure activity associated with cycling or swimming. Results from this pedometer study should therefore be interpreted in context with the study aim; to assess seasonal variation in day-to-day ambulatory activity.

\section{Conclusion}

Step counts in the sample of UK adults surveyed decreased significantly in the winter compared to the summer. This has methodological implications for future pedometer research, in that data collection restricted to one season may either overestimate or underestimate year round habitual ambulatory activity. In order to obtain a non-biased reflection of general day-to-day step count levels, pedometer studies should be conducted throughout the year. The current findings from this sample also have health implications, in that public health initiatives aiming to increase overall activity levels should acknowledge likely seasonal changes in ambulatory activity. Information should be disseminated about the possible physiological and psychological health implications of seasonally interrupting activity and effective physical activity policies should be seasonally tailored to provide opportunities to reduce this winter reduction in activity. 


\section{References}

Ainsworth B, Leon A, Richardson M, Jacobs D and Paffenbarger RJ. (1993). Accuracy of the College Alumnus Physical Activity Questionnaire. J Clin Epidemiol 46 (12): 1403-11.

Aittasalo M, Miilunpalo S and Suni J. (2004). The effectiveness of physical activity counseling in a work-site setting. A randomized, controlled trial. Patient Educ Couns 55 (2): 193-202.

Bassett DR, Ainsworth BE, Leggett SR, Mathien CA, Main JA, Hunter DC and Duncan GE. (1996). Accuracy of five electronic pedometers for measuring distance walked. Med Sci Sports Exerc 28 (8): 1071-7.

Bassett DR, Cureton AL and Ainsworth BE. (2000). Measurement of daily walking distancequestionnaire versus pedometer. Med Sci Sports Exerc 32 (5): 1018-23.

Behrens TK and Dinger MK. (2007). Motion sensor reactivity in physically active young adults. Res Q Exerc Sport 78 (1): 1-8.

Blair SN, Kohl HW, Gordon NF and Paffenbarger RSJ. (1992). How much physical activity is good for health? Annu Rev Public Health 13 99-126.

Cardon G, De Cocker K and De Bourdeaudhuji I (2006). Pedometer determined physical activity in Belgian adults. International Congress on Physical Activity and Public Health, Atlanta, USA.

CDC. (1997). Monthly estimates of leisure-time physical inactivity--United States, 1994. MMWR Morb Mortal Wkly Rep 46 (18): 393-7.

Chan CB, Ryan DA and Tudor-Locke C. (2004). Health benefits of a pedometer-based physical activity intervention in sedentary workers. Prev Med 39 (6): 1215-22.

Chan CB, Ryan DA and Tudor-Locke C. (2006). Relationship between objective measures of physical activity and weather: a longitudinal study. Int J Behav Nutr Phys Act 321.

Chief Medical Officer, (2004). At least five a week. Evidence on the impact of physical activity and its relationship to health. A report from the Chief Medical Officer. Department of Health, Health Improvement and Prevention.

Clemes SA, Griffiths PL and Hamilton SL. (2007). Four-week pedometer-determined activity patterns in normal weight and overweight UK adults. Int J Obes (Lond) 31 (2): 261-6.

Clemes SA, Hamilton SL and Lindley MR. (2008a). Four-week pedometer-determined activity patterns in normal weight, overweight and obese adults. Prev Med, in press.

Clemes SA, Matchett N and Wane SL. (2008b). Reactivity: an issue for short-term pedometer studies? Br J Sports Med, in press.

Dannenberg AL, Keller JB, Wilson PW and Castelli WP. (1989). Leisure time physical activity in the Framingham Offspring Study. Description, seasonal variation, and risk factor correlates. Am J Epidemiol 129 (1): 76-88. 
Department of Health (2005). Health Survey for England 2004. Updating of trend tables to include 2004 data. The Stationary Office Limited.

Dwyer T, Hosmer D, Hosmer T, Venn AJ, Blizzard CL, Granger RH, Cochrane JA, Blair SN, Shaw JE, Zimmet PZ and Dunstan D. (2007). The inverse relationship between number of steps per day and obesity in a population-based sample: the AusDiab study. Int J Obes (Lond) 31 (5): 797-804.

Eastep E, Beveridge S, Eisenman P, Ransdell L and Shultz B. (2004). Does augmented feedback from pedometers increase adults' walking behavior? Percept Mot Skills 99 392402.

Field A (2005). Discovering statistics using SPSS. London, Sage.

Haslam DW and James WP. (2005). Obesity. Lancet 366 (9492): 1197-209.

Hill JO and Melanson EL. (1999). Overview of the determinants of overweight and obesity: current evidence and research issues. Med Sci Sports Exerc 31 (11 Suppl): S515-21.

Hornbuckle LM, Bassett DR and Thompson DL. (2005). Pedometer-determined walking and body composition variables in African-American women. Med Sci Sports Exerc 37 (6): 1069-74.

House of Commons Health Committee (2004). Obesity. Third Report of Session 2003/04. Volume I., The Stationary Office Limited.

Huttunen P, Kokko L and Ylijukuri V. (2004). Winter swimming improves general wellbeing. Int J Circumpolar Health 63 (2): 140-4.

Lamb KL and Brodie DA. (1990). The assessment of physical activity by leisure-time physical activity questionnaires. Sports Med 10 (3): 159-80.

Le Masurier GC, Lee SM and Tudor-Locke C. (2004). Motion sensor accuracy under controlled and free-living conditions. Med Sci Sports Exerc 36 (5): 905-10.

Le Masurier GC and Tudor-Locke C. (2003). Comparison of pedometer and accelerometer accuracy under controlled conditions. Med Sci Sports Exerc 35 (5): 867-71.

Lee CJ, Lawler GS, Panemangalore M and Street D. (1987). Nutritional status of middle-aged and elderly females in Kentucky in two seasons: Part 1. Body weight and related factors. $\mathrm{J}$ Am Coll Nutr 6 (3): 209-15.

Magnus K, Matroos A and Strackee J. (1979). Walking, cycling, or gardening, with or without seasonal interruption, in relation to acute coronary events. Am J Epidemiol 110 (6): 724-33.

Matevey C, Rogers LQ, Dawson E and Tudor-Locke C. (2006). Lack of reactivity during pedometer self-monitoring in adults. Meas Phys Educ Exerc Sci 10 (1): 1-11.

Matthews CE, Freedson PS, Hebert JR, Stanek EJ, Merriam PA, Rosal MC, Ebbeling CB and Ockene IS. (2001). Seasonal variation in household, occupational, and leisure time 
physical activity: longitudinal analyses from the seasonal variation of blood cholesterol study. Am J Epidemiol 153 (2): 172-83.

Melanson EL, Knoll JR, Bell ML, Donahoo WT, Hill JO, Nysse LJ, Lanningham-Foster L, Peters JC and Levine JA. (2004). Commercially available pedometers: considerations for accurate step counting. Prev Med 39 (2): 361-8.

Merrill RM, Shields EC, White GL and Druce D. (2005). Climate conditions and physical activity in the United States. Am J Health Behav 29 (4): 371-81.

Met Office (2006). UK climate and weather statistics. Crown Copyright. http://www.metoffice.gov.uk/climate/uk, assessed May 2006.

National Statistics (2007), Neighbourhood statistics. Crown Copyright. http://neighbourhood.statistics.gov.uk/ assessed November 2007.

Partonen T and Lonnqvist J. (1998). Seasonal affective disorder. Lancet 352 (9137): 1369-74.

Pietrobelli A, Rubiano F, St-Onge MP and Heymsfield SB. (2004). New bioimpedance analysis system: improved phenotyping with whole-body analysis. Eur J Clin Nutr 58 (11): 1479-84.

Pivarnik JM, Reeves MJ and Rafferty AP. (2003). Seasonal variation in adult leisure-time physical activity. Med Sci Sports Exerc 35 (6): 1004-8.

Richardson MT, Leon AS, Jacobs DR, Ainsworth BE and Serfass R. (1994). Comprehensive evaluation of the Minnesota Leisure Time Physical Activity Questionnaire. J Clin Epidemiol 47 (3): 271-81.

Rowe DA, Mahar MT, Raedeke TD and Lore J. (2004). Measuring physical activity in children with pedometers: Reliability, reactivity, and replacement of missing data. Pediatr Exerc Sci 16 (343-354):

Sallis JF and Saelens BE. (2000). Assessment of physical activity by self-report: status, limitations, and future directions. Res Q Exerc Sport 71 (2 Suppl): S1-14.

Schneider PL, Crouter SE and Bassett DR. (2004). Pedometer measures of free-living physical activity: comparison of 13 models. Med Sci Sports Exerc 36 (2): 331-5.

Sequeira MM, Rickenbach M, Wietlisbach V, Tullen B and Schutz Y. (1995). Physical activity assessment using a pedometer and its comparison with a questionnaire in a large population survey. Am J Epidemiol 142 (9): 989-99.

Shin K, Schaffer A, Levitt AJ and Boyle MH. (2005). Seasonality in a community sample of bipolar, unipolar and control subjects. J Affect Disord 86 (1): 19-25.

Suter E, Marti B, Tschopp A and Wanner HU. (1991). [Effects of jogging on mental wellbeing and seasonal mood variations: a randomized study with healthy women and men]. Schweiz Med Wochenschr 121 (35): 1254-63. 
Swartz AM, Bassett DR, Moore JB, Thompson DL and Strath SJ. (2003). Effects of body mass index on the accuracy of an electronic pedometer. Int J Sports Med 24 (8): 588-92.

Tudor-Locke C and Bassett DR. (2004). How many steps/day are enough? Preliminary pedometer indices for public health. Sports Med 34 (1): 1-8.

Tudor-Locke C, Bassett DR, Swartz AM, Strath SJ, Parr BB, Reis JP, Dubose KD and Ainsworth BE. (2004a). A preliminary study of one year of pedometer self-monitoring. Ann Behav Med 28 (3): 158-62.

Tudor-Locke C, Burkett L, Reis JP, Ainsworth BE, Macera CA and Wilson DK. (2005). How many days of pedometer monitoring predict weekly physical activity in adults? Prev Med 40 (3): 293-8.

Tudor-Locke C, Ham SA, Macera CA, Ainsworth BE, Kirtland KA, Reis JP and Kimsey CD, Jr. (2004b). Descriptive epidemiology of pedometer-determined physical activity. Med Sci Sports Exerc 36 (9): 1567-73.

Tudor-Locke C, Williams JE, Reis JP and Pluto D. (2002). Utility of pedometers for assessing physical activity: convergent validity. Sports Med 32 (12): 795-808.

Tudor-Locke CE and Myers AM. (2001). Challenges and opportunities for measuring physical activity in sedentary adults. Sports Med 31 (2): 91-100.

Uitenbroek DG. (1993). Seasonal variation in leisure time physical activity. Med Sci Sports Exerc 25 (6): 755-60.

Van Staveren WA, Deurenberg P, Burema J, De Groot LC and Hautvast JG. (1986). Seasonal variation in food intake, pattern of physical activity and change in body weight in a group of young adult Dutch women consuming self-selected diets. Int J Obes (Lond) 10 (2): 133-45.

WHO. (2000). Obesity: preventing and managing the global epidemic. Report of a WHO consultation. World Health Organ Tech Rep Ser 894 i-xii, 1-253. 
Table I. A summary of the temperature, sunshine hours and rainfall volume recorded during each monitoring frame

\begin{tabular}{lccccc}
\hline & \multicolumn{3}{c}{ Temperature (oC) } & Sunshine & Rainfall \\
& Mean & Min & Max & hours & volume \\
& $(\mathrm{mm})$ \\
\hline Summer 2005 & 15.9 & 11.2 & 20.5 & 583.3 & 174.8 \\
Winter 2006 & 4.0 & 1.2 & 6.8 & 177.9 & 144.1 \\
\hline
\end{tabular}


Table II. Participant summer and winter anthropometric and step count data

\begin{tabular}{lcccccc}
\hline & \multicolumn{2}{c}{ Summer study } & \multicolumn{2}{c}{ Winter study } & \multicolumn{2}{c}{ Between season differences } \\
& Mean & SD & Mean & SD & $t$-value & $p$-value \\
\hline BMI (kg/m2) & 26.1 & 5.1 & 26.3 & 5.3 & 2.372 & 0.020 \\
\% Body fat & 25.8 & 10.4 & 27.2 & 10.5 & 5.722 & $<0.001$ \\
Mean daily step count (steps/day) & 10417 & 3055 & 9132 & 2841 & 6.627 & $<0.001$ \\
\hline
\end{tabular}




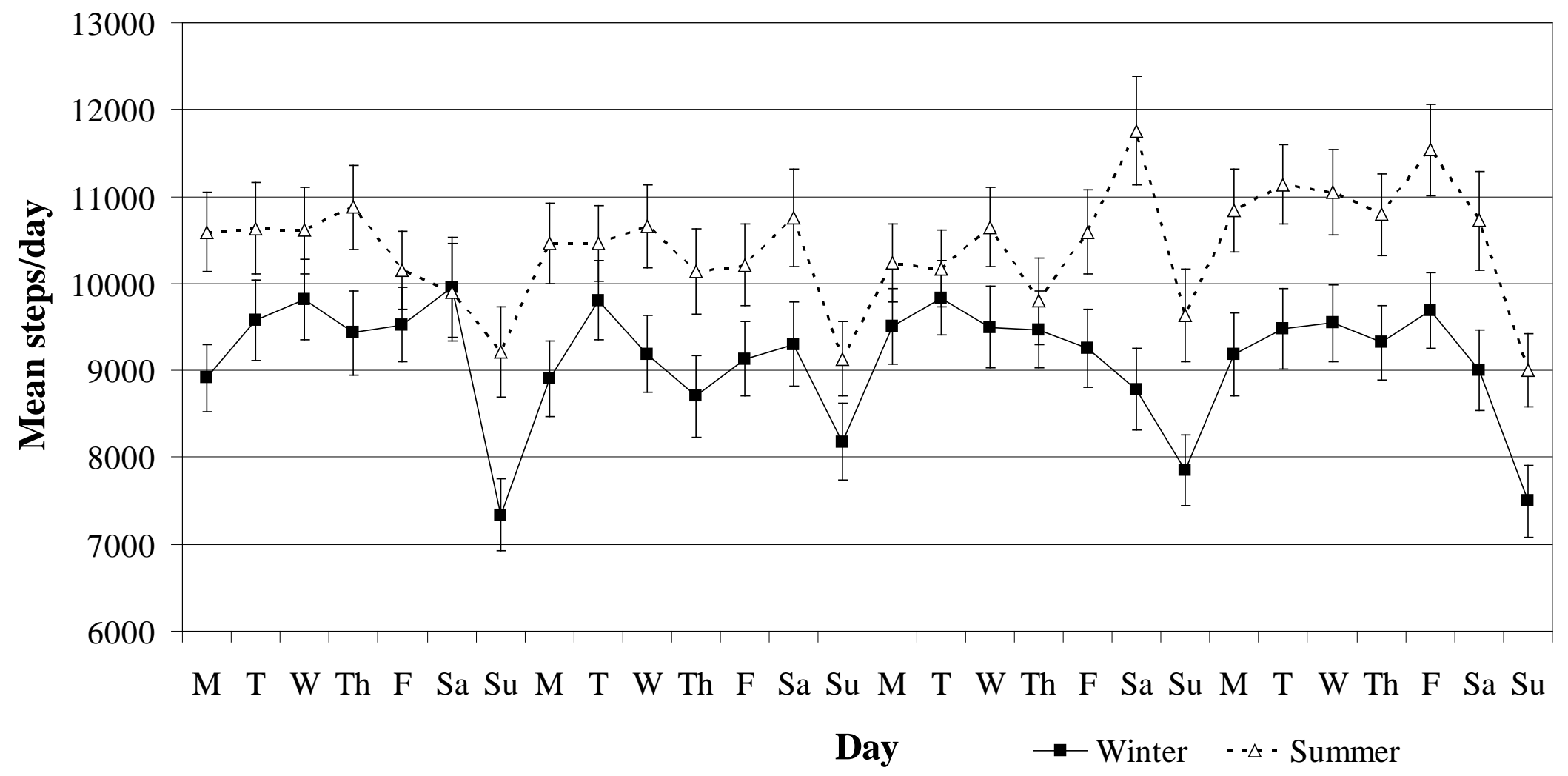

Figure 1. Mean (SE) daily step counts reported over the four-week summer and winter monitoring periods $(n=96)$. 
Table III. Mean daily step counts reported on each day of the week over the four-week summer and winter monitoring periods, and day-specific seasonal changes in steps taken (winter minus summer).

\begin{tabular}{cccccccccc}
\hline Day of Week & \multicolumn{2}{c}{ Summer steps/day } & \multicolumn{3}{c}{ Winter steps/day } & \multicolumn{2}{c}{ Between season differences } & \multicolumn{2}{c}{ Seasonal change steps/day } \\
& Mean & SD & Mean & SD & $t$-value & $p$-value & \multicolumn{2}{c}{ Mean } & SD \\
\hline Monday & 10531 & 3728 & 9128 & 3422 & 5.490 & $<0.001$ & -1403 & 2504 \\
Tuesday & 10602 & 3758 & 9674 & 3827 & 3.412 & 0.001 & -928 & 2664 \\
Wednesday & 10741 & 3882 & 9511 & 3692 & 4.509 & $<0.001$ & -1230 & 2673 \\
Thursday & 10402 & 3810 & 9233 & 3684 & 4.283 & $<0.001$ & -1169 & 2673 \\
Friday & 10530 & 3597 & 9258 & 3071 & 3.770 & $<0.001$ & -1273 & 3181 \\
Saturday & 10771 & 4121 & 9262 & 3767 & 3.828 & $<0.001$ & -1509 & 3863 \\
Sunday & 9246 & 3471 & 7714 & 3060 & 4.090 & $<0.001$ & -1532 & 3671 \\
Day of week main effect & $F=4.593, p<0.01$ & $F=7.927, p<0.001$ & & & & $F=0.923, p=0.463$
\end{tabular}

Bonferroni corrected pairwise comparisons identified Sunday step counts as significantly lower than all other days during both seasons, summer $(p<0.05)$ and winter $(p \leq 0.01)$. 